\title{
Response Recovery Cycles in the Visual Cortex and Superior Colliculus Following Conditioning "ON" and "OFF" Stimulation in the Rabbit
}

\author{
STÉPHANE MOLOTCHNIKOFF AND MICHEL DUBUC
}

SUMMARY: The responsiveness of the visual cortex (VC) and superior colliculus (SC) was simultaneously compared following conditioning " $O N$ " or "OFF' stimulation, in the rabbit.

Average evoked responses were recorded simultaneously from the visual cortex and superior colliculus. "ON"' or "OFF"' steps constituted the conditioning stimuli whereas the test stimulus consisted of optic nerve stimulation. All evoked responses exhibited a reversal of their polarity when the electrode was moved in the dorsoventral direction (Negative-Positive in the SC, Positive-

RÉSUMÉ: Par la technique du double choc, le cycle de récupération postréactionnelle (RPR) a été étudié simultanément au niveau du cortex visuel (CV) et au niveau du colliculus supéricur (CS), chez le lapin. Les chocs conditionnant étaient de deux types. soit la stimulation 'ON', soit la stimulation "OFF"'. Les réponses tests ont été évoquées par une stimulation du nerf optique, court-circuitant ainsi l'étape rétinienne. Toutes les réponses ont présenté une inversion de polarité dorsoventrale du CV et du CS, assurant ainsi une origine post-synaptique. Les résultats montrent que l'excitabilité

From the Département de Sciences biologiques, Université de Montréal, C.P 6128, Montréal (Qué.), Canada, $\mathrm{H} 3 \mathrm{C}$ 3J7

Reprint requests to Professor Stéphane Molotchnikoff, Département de Sciences biologiques, Université de Montréal C.P. 6128. Montréal, Canada $\mathrm{H} 3 \mathrm{C} 3 \mathrm{~J} 7$.

This research was supported by grant No. A 6943 of the National Research Council of Canada.

M. Dubuc was a holder of Quebec scholarship (D.G.E.S.)

We wish to acknowledge the technical assistance of Mr. J. R. Brunette who was supported by grant No. MA 6593 of the Medical Research Council of Canada.
Negative in the VC). This assured the somato-dentritic origin of the potentials. The results showed that responsiveness in both structures was significantly higher following an 'OFF', stimulus than after an "ON" step. Collicular responsiveness was higher than in the $V C$ when the same conditioning stimulus was applied. The spatial distribution of the source of "OFF" responses was circumscribed to the ventral part of the superficial layer of the superior colliculus. These results suggest specific properties associated with the brightening and dimming systems.

post-réactionnelle est significativement plus élevée après une stimulation conditionnante "OFF"' qu'après un conditionnement de type opposé, c'est-à-dire “ON'.

Pour un même type de stimulation conditionnante, la réactivité colliculaire est plus élevée que celle du cortex visuel. Au niveau du colliculus supérieur, les potentiels évoqués par la stimulation " $O F F$ ' présentent une distribution spatiale circonscrite à la portion ventrale des couches superficielles du CS. Cette étude permet d'associer des propriétés spécifiques aux systèmes "ON" et "OFF".

\section{INTRODUCTION}

Turning a light $\mathrm{ON}$ or OFF activates two distinct neural systems in the visual pathways and centers. These are the B (Brightening) and D (Dimming) systems, respectively (Jung, 1973). This duality originates with the presence of retinal bipolar cells with receptive fields organized as either "center-ON" or "centerOFF', (Werblin and Dowling, 1969). The same organization and therefore the same duality is found in neural networks in the visual pathways and centers of all vertebrates (Rodieck, 1973; Freund, 1972; Magnussen and Glad, 1975).

While a great deal of work has been concerned with the study of visual evoked responses to a brief light flash: (Stériade, 1969; Creutzfeldt and Kuhnt, 1973), few studies have centered on evoked response to an OFF stimulation. It was recently shown in rabbits that responses evoked by OFF stimulation are characterized by the presence of a greater number of rapid waves of an oscillatory type than are responses evoked by ON stimulation (Molotchnikoff et al., 1975, 1976). This enhanced oscillation may reflect more intense activity of reverberatory circuits in the superior colliculus and visual cortex (Dubuc, 1976)

These findings led us to investigate the functional properties of the $\mathrm{ON}$ and OFF systems. This study presents an analysis of recovery of response (RR) following excitation by $\mathrm{ON}$ and OFF conditioning stimuli in the rabbit.

\section{Preparation}

METHOD

Twenty-five New Zealand rabbits 
weighing between 2 and $3 \mathrm{~kg}$ were used in this study. They were anesthetized with sodium pentabarbital $(24 \mathrm{mg} / \mathrm{kg})$, paralyzed with A Gallamine $(10 \mathrm{mg} / \mathrm{kg} / \mathrm{h})$, and connected to an artificial respirator. A local anesthetic (Xylocaine) was applied subcutaneously to all pressure points and incision sites. To minimize pulsating movement of the brain, the cerebello-bulbar cistern was drained. The animals were then placed in a stereotaxic apparatus (Kopf) which had been modified so as not to obstruct the visual field. Trepanation permitted stereotaxic access to the superior colliculus and Area I of the visual cortex (Sawyer et al., 1954; Thompson et al., 1950). The contralateral eye was closed throughout the experiment.

\section{Stimulation}

Two types of stimulation were used. (1) The optic nerve was stimulated at the point of exit from the back of the eye using the method described by Lederman and Noell (1968); electrical stimulation was of short duration $(0.05-2.00 \mathrm{msec})$. In order to recruit all the fibers; stimulation intensity was fixed at 5 times the threshold value ( 3 to 4 volts) which was determined by the smallest visible potential method (Dubuc 1976). (2) Photic stimulation was by means of a tungsten filament fed by direct current. Intensity of the light beam was set at 3.5 F.C. at the cornea. ON and OFF stimulation was produced by opening and closing an electromagnetic shutter.

ON stimulation was applied every 2 seconds and was of 1 -second duration. Thus, each stimulation cycle was composed of one dark and one light period of equal duration (1 sec). These parameters were chosen since they provided a flash long enough to separate the OFF response sufficiently from the $\mathrm{ON}$ reaction while also limiting the rapid effects produced by light adaptation (Armington 1974).

\section{Recording}

Collicular and contralateral cortical potentials were recorded with monopolar stainless steel electrodes having a diameter of $100 \mu \mathrm{m}$ and completely insulated (with
INSL-X-33) except at the tip. The pre-amplifier (GRASS, P511) had a pass band of $1-300 \mathrm{~Hz}$. Potentials were monitored on a cathode ray oscilloscope (Tektronix) and photographed. A mean of 64 evoked responses was effected by an averager (Med 80), then retraced on the oscilloscope. The equipment (electrical and photic stimulators, recorders, averager) was synchronized by a programmer (Device).

\section{Electrode Implantation}

It was essential to ensure the post-synaptic origins of potentials evoked by photic and electrical stimulation in this analysis of response recovery in the superior colliculus and visual cortex. The cytoarchitecture of the two structures is advantageous in this respect. They contain cellular elements which are arranged in a radial manner (Buser, 1955, 1956; Creutzfeldt and Kuhnt, 1973; Landau, 1967; Sterling, 1971; Szentagothäi, 1973; Vanegas et al., 1974).

When the synaptic distribution is limited to a circumscribed zone on the dendritic arborizations, the synaptic activity of these neurons generates an electrical field which forms a dipole. Consequently, a reversal in polarity of the evoked potentials occurs when the recording electrode is lowered in a direction parallel to that of the dipole. This is characteristic of the activity of a somato-dendritic axe (Buser 1956) and, therefore, of post-synaptic activity. This feature was exploited to ensure the cellular origin of recorded responses. All potentials analyzed in this study showed a reversal of polarity when the recording electrode was moved in a dorso-ventral direction in the superior colliculus and visual cortex. It is well established (Buser, 1956; Goodale, 1973, Molotchnikoff et al., 1975; Tamai and Ogawa, 1972) that collicular responses are negative at the surface and positive when recorded deep in the structure. Conversely, cortical responses are positive at the surface and become negative with intracortical penetration (See: Creutzfeldt and Kuhnt, 1973; Molotchnikoff et al., 1975). To maximize uniformity of evoked potentials across experiments, the electrode was always placed at the site where the reversed potentials showed the greatest amplitude (see also fig. 4). Response amplitude was measured from the baseline to the top of the wave. The rate of decrease of this amplitude was calculated as a percentage of the response obtained in the absence of the conditioning stimulus (control response). Then an angular transformation (Lison 1968) where $\mathrm{P}$ is expressed as the sin of $\operatorname{arc} \sqrt{\mathrm{P} / 100}$ permitted statistical analysis of the variance of these percentages. At the end of each experiment, an electrolytic lesion was made to provide verification of the electrode site.

\section{Results}

Recovery of response $(R R)$ at the superior colliculus

Recovery of response was studied by means of paired stimulation. In the results presented in the next two sections, the conditioning stimulus consisted of either ON or OFF photic stimulation while the test stimulus was always electrical stimulation of the optic nerve.

\section{a) $R R$ following an $O N$ conditioning stimulus}

Following an ON conditioning stimulus, responsiveness of the superior colliculus decreased rapidly reaching a minimum when the interval separating the two stimuli was 50 msec (Fig. 1A2 and B). It can be seen that the response amplitude found for an interval of $50 \mathrm{msec}$ was $95 \mu \mathrm{V}$ (Fig. 1, 2). traces 2 to 6 (Fig. 1) show the results of a typical experiment which reflects variation in response amplitude as the test stimulus was increasingly separated in time from the conditioning stimulus.

Figure 1B illustrates changes in responsiveness (mean of 25 experiments) and shows 3 successive phases in the temporal recovery of $\mathrm{RR}$ after a conditioning $\mathrm{ON}$ stimulus. In the first phase, there was an abrupt drop to $50 \%$ of the control amplitude, becoming minimal about 50 msec after the conditioning stimulus. This corresponds to the point in time when the relative refractory period 


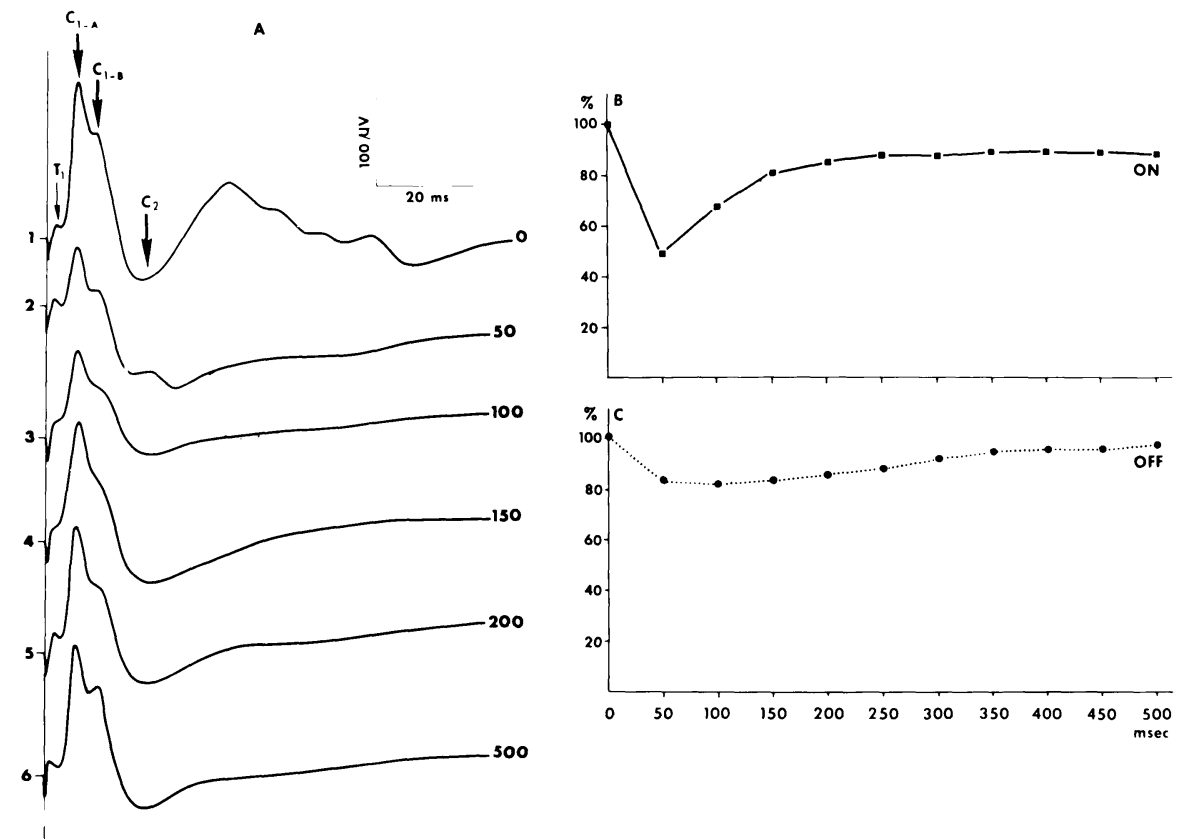

Figure 1-Responsiveness of the Superior colliculus (SC) following conditioning ON and OFF stimuli. A - Typical averaged responses evoked by optic nerve stimulation. Each trace represents the average for 64 successive stimulations. Right hand numbers indicate the interval between light $\mathrm{ON}$ and optic nerve stimulation in msec. The amplitudes of the potentials were measured from the base line to the highest peak ( $\mathrm{C}_{1-\mathrm{A}}$ wave). The evoked responses presented a complex waveform. The positive humps are indicated as: $\mathrm{C}_{1-\mathrm{A}}$ and $\mathrm{C}_{1-\mathrm{B}}$ whereas the negative wave is labelled $C_{2}$. All collicular waves reversed their polarity as the electrode penetrated the S.C. except $T_{1}$, which possibly was of presynaptic origin. Positivity upward. B - Time course of responsiveness following light ON. C Time course of responsiveness following light OFF in B and C: abscissa indicates interstimulus interval; ordinate gives amplitude of the test response evaluated in percent of the unconditioned amplitude. In all cases the amplitude of the $\mathrm{C}_{1-\mathrm{A}}$ was used. Note that the refractoriness was much greater when the conditioning stimulus was a brightening (ON) step.

is the most intense. In the second phase, evoked responses to the test stimulus increased in amplitude, denoting an augmentation in responsiveness. This phase which occurred between 50 and $200 \mathrm{msec}$ after the conditioning stimulus, was characterized by rapid recovery of responses with amplitudes increasing from 50 to $80 \%$ of the control level. Following this period, recovery stabilized at around $80 \%$ even when the interstimulus interval was extended from 200-500 msec. This plateau constituted the third phase of recovery.

\section{b) $R R$ following an OFF condition- ing stimulus}

Application of a conditioning OFF stimulus which consisted of cessation of the light flash used above results in a temporal course of re- produces greater responsiveness than does excitation of the ON system.

\section{Recovery of response $(R R)$ in the visual cortex}

Since analysis of cortical responsiveness was made simultaneously with that of the superior colliculus, $\mathrm{ON}$ and OFF conditioning stimuli and the test shock were of the same intensity and duration as reported above.

\section{a) $R R$ following an $O N$ conditioning stimulus}

As in the colliculus, recovery seemed to proceed in three distinct successive phases (Fig. 2B). Figure 2 presents the results of an experiment in which there was a great attenuation of potentials evoked by the test shock when it was applied 50 msec after the conditioning stimulus. In Figure 2B, the curve shows variation in responsiveness at the visual cortex after an $\mathrm{ON}$ conditioning stimulus. In the first phase, there was a sudden drop in reactivity which fell to $20 \%$ when the two stimuli were separated by $50 \mathrm{msec}$. Responsiveness was $50 \%$ for the same interval at the level of the superior colliculus $(0.001<\mathrm{P}<0.01)$.

There was a rapid return of responsiveness $(20-60 \%)$ during the second phase which extended from 50 to $200 \mathrm{msec}$ (Fig. 2B). Then followed the third phase: a plateau stage during which recovery was very slow. From 200 to $500 \mathrm{msec}$, response amplitude was stable at around $55 \%$ of the control value. Collicular responsiveness was $80 \%$ during the plateau phase.

\section{b) RR after OFF stimulation}

Following a conditioning OFF stimulus, the course of cortical responsiveness (Fig. 2C) was parallel to that found in the superior colliculus for the same conditioning stimulus (Fig. 1C). The difference lies in the intensity of the refractory period which was smaller in the superior colliculus (Fig. 1C) than in the visual cortex. Its evolution was, also, different from that obtained with an $\mathrm{ON}$ conditioning stimulus. Three phases could not be distinguished during cortical RR after OFF stimulation; after the initial drop at 

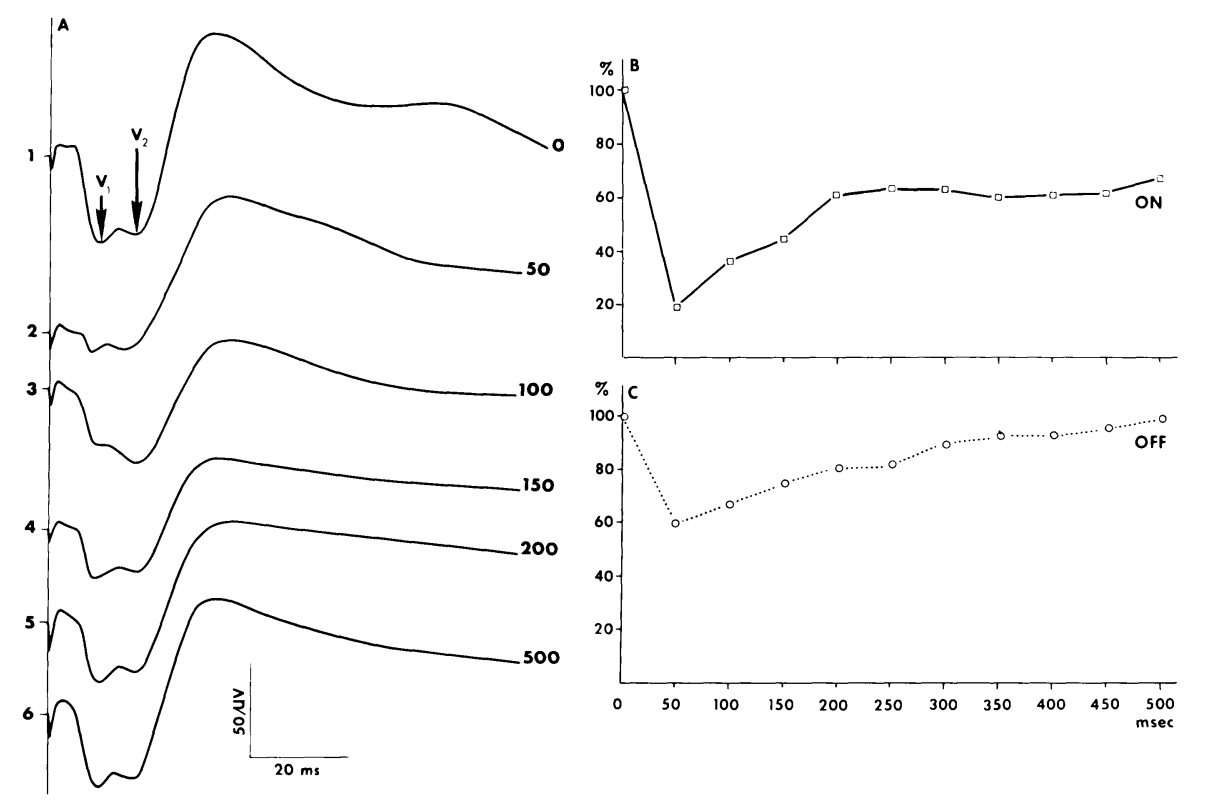

Figure 2-Responsiveness of Visual cortex (VC) following conditioning ON and OFF stimuli. A - Typical averaged responses evoked by optic nerve stimulation. Each trace represents the average for 64 successive stimulations. Right hand numbers indicate the interval between light $\mathrm{ON}$ and optic nerve stimulation in msec. The amplitude of the potentials were measured from the baseline to the lowest peak: $\mathrm{V}_{1}$ wave. The evoked responses had a simpler wave form than in the superior colliculus. Two negative potentials were consistently identified, $V_{1}$ and $V_{2}$, and both reversed their polarity with cortical penetration of the electrode. Positivity upward. $\mathrm{B}$ - Time course of responsiveness following light $\mathrm{ON}$. C - Time course of responsiveness following light $\mathrm{OFF}$. In $\mathrm{B}$ and $\mathrm{C}$ : abscissa indicates inter-stimulus interval; ordinate gives amplitude of the test response evaluated in percent of the unconditioned amplitude. In all cases the amplitude of the $\mathrm{V}_{1}$ potential was used. Note that the refractoriness was much greater when the conditioning stimulus was a brightening step.

$50 \mathrm{msec}$, recovery of response proceeded linearly until it reached the control value. Unlike the case for an ON conditioning stimulus, RR never showed a plateau phase.

\section{Paired electrical stimulation}

The time course of the refractory period in the superior colliculus and visual cortex can be evaluated in the absence of retinal activity by applying paired electrical stimulation to the optic nerve alone. Therefore, the first photic conditioning stimulus used above was replaced by electrical stimulation of the optic nerve, thereby eliminating evoked retinal participation. As was found above, the decline in responsiveness of the superior colliculus was very weak. When the inter-stimulus interval was between 50 and $200 \mathrm{msec}$, there was no discernable diminution of response to the test stimulus in the superior colliculus (Fig. 3, traces
These results suggest a supranormal phase which allows facilitation of the response. The absence of such a facilitatory period with photic conditioning stimulation would indicate that it originates at the geniculocortical pathway and that retinal evoked activity interferes with its development.

\section{Intra-collicular exploration}

We have just seen that tectal and cortical responsiveness varies in intensity and temporal course according to whether conditioning stimulation was of the ON or OFF type. It is also possible to demonstrate that $\mathrm{ON}$ and OFF responses have a different spatial distribution within the superior colliculus. Schaeffer (1970) showed that tectal ON discharges were more pronounced than OFF, in the rabbit.

During this series of experiments, potentials evoked by photic ON and OFF stimulation were recorded at different penetration depths in the superficial layers of the superior colliculus: at the stratum griseum superficiale which contains the majority of photosensitive cellular elements, and the stratum opticum which is in major part composed of axon fibers of retinal origin (Sterling 1971). Histological examination of electrolyzed sites permitted localization of the electrode tip relative to the surface of the colliculus and to the stratum opticum (the latter is indicated by a solid arrow, Fib. 4). Figure 4 seems to suggest an unequal spatial distribution of $\mathrm{ON}$ and OFF potentials. At the surface of the superior colliculus, the $\mathrm{ON}$ response (Fig. 4, trace 1) stands out because of its relatively high amplitude (30 $\mu \mathrm{V}$ for the positive wave); the OFF response (Fig. 4, trace 2) recorded at the same site was of very low amplitude: it is barely visible above the background noise. Even though the initial slope of the ON response showed positive polarity, a strong negative component with greater latency was visible (Fig. 4, trace 1). With deeper penetration, when the electrode tip was about half-way between the surface and the stratum opticum, ON (trace 3) and OFF (trace 4) responses were positive and 
of high amplitude (325 and $250 \mu \mathrm{V}$, respectively).

When the electrode tip was at the point separating the stratum griseum' superficiale from the stratum opticum, ON (trace 5) and OFF (trace 6) responses were of almost equal amplitude $(350 \mu \mathrm{V})$. This was the site at which $\mathrm{RR}$ recordings reported above were made. Indeed, it was at this level that the OFF response had its highest amplitude since slightly deeper, it was much attenuated (trace 8); the ON response (trace 7), although diminished $(70 \mu \mathrm{V})$, maintained a relatively high amplitude. Thus, it seems that neural elements which generate ON and OFF activity are not equally distributed. The ON responses are distributed in a more uniform manner throughout the thickness of the superficial layers while those producing the OFF response are circumscribed to the depths of superficial collicular layers. It was impossible to find an analogous phenomenon in the visual cortex.

\section{DISCUSSION}

The most striking observation in this study was a greater reduction of collicular and cortical responsiveness following an $\mathrm{ON}$ conditioning stimulus than after an OFF (Fig. 1 and 2, B,C). This difference reflects the specificity of the $\mathrm{ON}$ and $\mathrm{OFF}$ systems. It is difficult to attribute the differences to experimental parameters: intensity of test stimulus, recording site, length of dark and light periods preceding $\mathrm{ON}$ and OFF conditioning stimuli since the parameters were identical in the experimental conditions. Furthermore, although they were opposite in phase, the magnitude of $\mathrm{ON}$ and OFF conditioning stimuli were also identical.

The greater responsiveness after an OFF conditioning stimulus may derive from adaptations to evolutionary forces operating on the species. In fact, the rabbit shows a strong tendency to be active at twilight or even at night (Grasset and Dekeyser, 1955). It is not surprising that the retina primarily contains photoreceptors specialized for scotopic

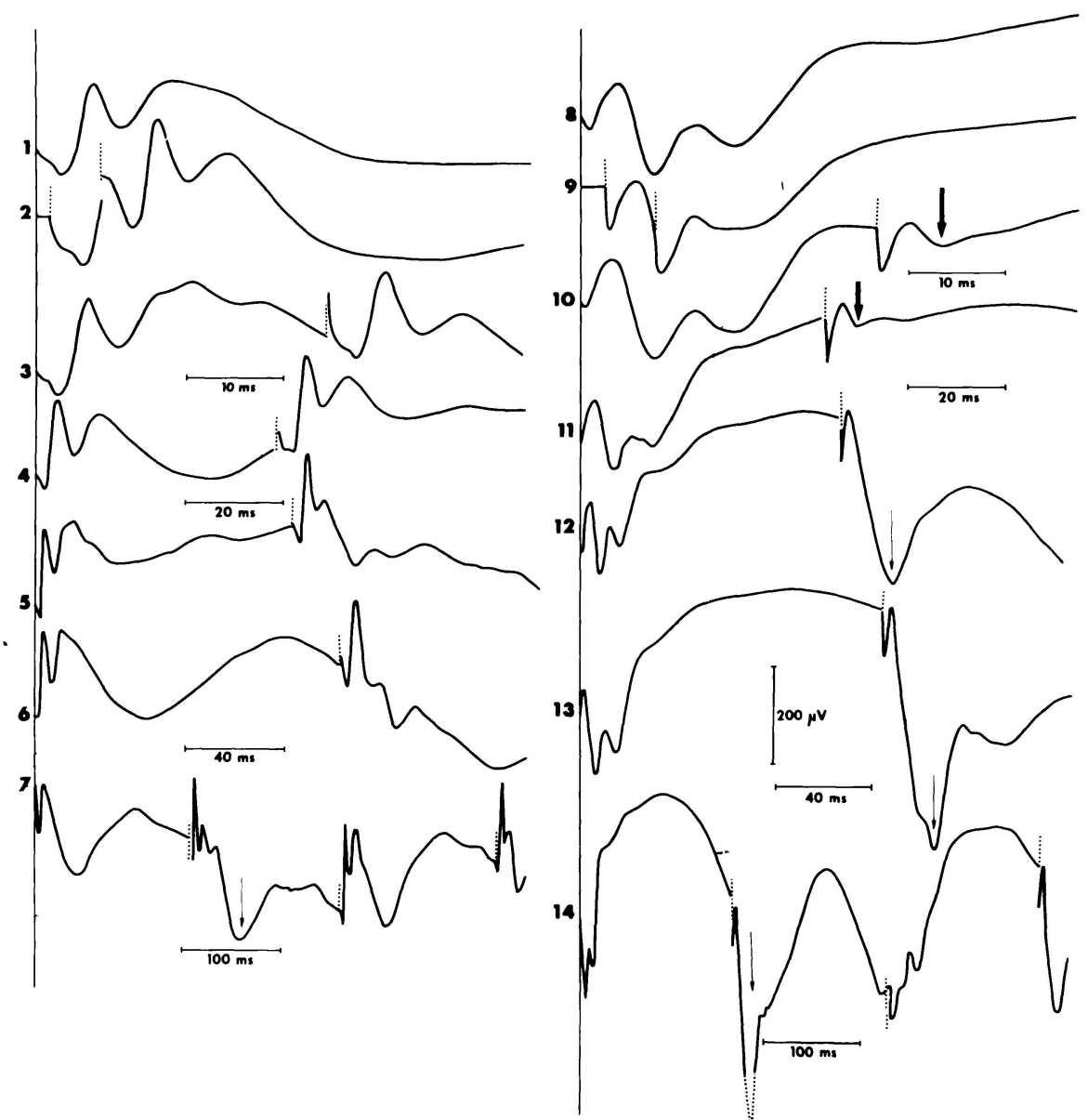

Figure 3-Responsiveness of the superior colliculus (Traces 1 to 7) and the visual cortex (Traces 8 to 14) following electrical excitation of the optic nerve as a conditioning stimulus. The test stimulus was identical to the conditioning pulse and was presented after a delay. Voltage calibration was the same for the two structures. The solid line at the beginning of each trace denotes the trigger time of the oscilloscope. The conditioning stimulus was applied after a slight delay (broken line). This line is fused with the trigger line at slow sweep speed. In traces 1 and 8 , no conditioning stimulus is present. The paired shocks were applied with a sufficient delay, $10 \mathrm{msec}$; in order to permit complete recovery between two successive testings, except in traces 7 and 14 where four successive pulses were applied. At the collicular level (traces 1 to 7 ) the test response exhibited an amplitude which was about equal to the unconditioned response and thus revealed a very weak refractoriness of the superior colliculus. Facilitatory phase of a late potential (trace 7 , arrow) was observed when the inter-stimulus interval was $165 \mathrm{msec}$. At the cortical level (traces 8 to 14), the low amplitude of the test response indicated a decrease of responsiveness between 30 and $60 \mathrm{msec}$ (traces 10 and 11, arrow). With longer intervals a facilitatory phase was recorded (traces 12, 13, 14, arrow) for the second shock only. All traces are averaged responses over 64 successive stimulations.

vision (i.e. rods); cones are scarce and atypical (Prince 1964).

Results presented in Fig. 4 add another characteristic which distinguishes between the ON and OFF systems. As this figure shows, OFF responses derive from a more limited area than do ON responses. This region lies in the depths of the superficial layers of the superior col- liculus. This more restricted localization of recording sites for OFF responses may reflect a more limited distribution of synaptic contacts and greater specialization (Marty and Sherrer 1964) of the OFF system in the superior colliculus. This hypothesis implies that the two systems did not evolve in a completely parallel manner. Muntz's (1962) re- 

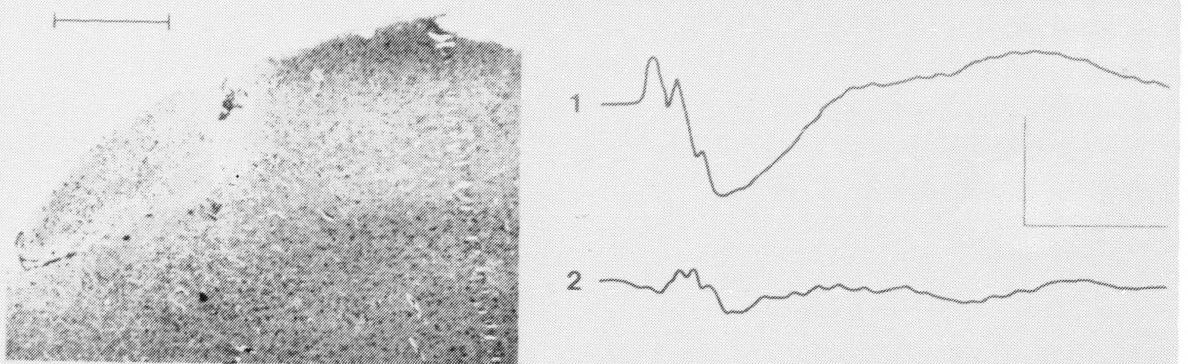

2
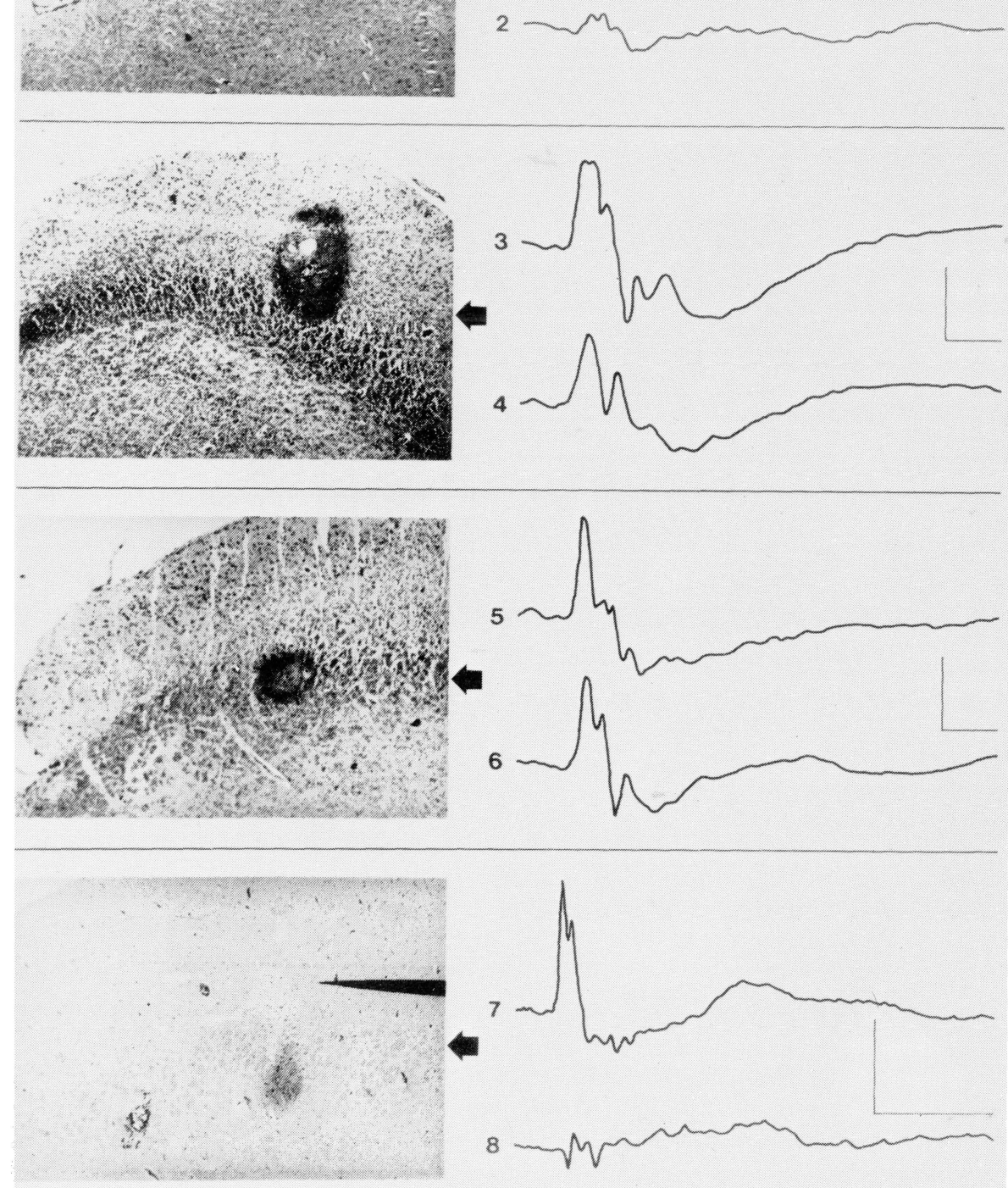

Figure 4-Depth profile of ON and OFF responses of the superior colliculus. The lesion of each photomicrograph indicates the position of the electrode tip; evoked responses corresponding to that level are found to the right. Traces $1(\mathrm{ON})$ and 2 (OFF) were recorded just below the collicular surface. Traces 3 and $5(\mathrm{ON}), 4$ and 6 (OFF) were recorded deeper in the stratum griseum superficiale. Note that the amplitudes of the ON and OFF responses were comparable when the electrode was located slightly above the stratum opticum (indicated by an arrow). Below that level (traces 7 and 8 ) the $O N$ response still showed considerably higher amplitude than the OFF response. The marker indicates a region of numerous perikarya. Positivity upward. Calib. photo. 500 microns. Trace Calib.: $50 \mu \mathrm{V}, 100$ msec for 1, 2, 7, 8: $250 \mu \mathrm{V}, 30 \mathrm{msec}$ for 3, 4, 5, 6. Evoked potentials are averaged responses over 64 successive presentations. sults on the frog raise some interesting points which lend support to this hypothesis. He found a complete absence of OFF responses in the lateral geniculate body in these animals although it was possible to evoke response to both types of stimulation at the tectum. These observations reveal that the two systems are dissociated at this level of phylogeny.

At the cellular level, the $\mathrm{ON}$ and OFF systems in the visual pathways and centers have physiologically identical properties (Hubel and Wiesel, 1962; Jung, 1973). On the other hand, each can be differentiated by its specific properties: greater rhythmical activity in the OFF system (Molotchnikoff et al., 1975, 1976), difference in recovery of responsiveness, and different spatial distribution in the superior colliculus.

Our results also show that for the same conditioning stimulus, collicular reactivity is significantly greater than that of the geniculocortical system. Many reports (Berman and Cynader, 1972; Jeannerod, 1974; Schiller and Koerner, 1974; Wickelgren and Sherling, 1969) have demonstrated the complementary functions of the retino-tectal and retino-strial systems. The superior colliculus is primarily implicated in visuo-motor reflex activities while the visual cortex subserves mainly perceptual functions. From this point of view, it is not surprising that the superior colliculus presents greater responsiveness to $\mathrm{ON}$ and $\mathrm{OFF}$ conditioning stimulation than does the visual cortex.

\section{ACKNOWLEDGEMENTS}

We would like to thank Dr. J. M. Demers for revision of the text, Mrs. D. Harvey and Mrs. A. Laperrière for typing the manuscript. We are also grateful to Mrs. H. Farid and Mr. J. L. Verville for perparing the illustrations.

\section{REFERENCES}

ARMINGTON, J. C. (1974). The electroretinogram. Academic Press. N.Y. 317-320.

BERMAN, N., CYNADER, M. (1972). Comparison of receptive field organization of the superior colliculus in Siamese and normal cats. Journal of Physiology, Lond. $224,363-389$ 
BUSER, P (1955). Etude de l'activité électrique du lope optique des vertébrés inférieurs (1). Journal de Physiologie, Paris, 47, 737-768.

BUSER, P (1956). Etude de l'activité électrique du lobe optique des vertébrés inférieurs (II). Journal de Physiologie, Paris, 48, 49-71.

CREUTZFELD, O. D., KUHNT, U. (1973). Electrophysiology and topographical distribution of visual evoked potentials in animals. In: Handbook of Sensory Physiology Vol. VII/3A, Ed. Jung, Berlin-Heidelberg. New York. 595-646.

DUBUC, M. (1976). Etude comparative des potentiels évoqués simultanément au collicule supérieur et au cortex visuel par le "ON" et le "OFF" d'un éclair lumineux chez le lapin. Thèse de Maîtrise, Université de Montréal.

FREUND, H J (1972). Neuronal mechanisms of the lateral geniculate body. In: Handbook of Sensory Physiology Vol. VII/3B, Ed. R. Jung, Berlin-Heidelberg. New York, 177-246.

GOODALE, M. A. (1973). Cortico-tectal and intertectal modulation of visual responses in the rat's superior colliculus. Experimental Brain Research, 17, 75-86.

GRASSET, P P., DEKEYSER, P L. (1955). Traité de Zoologie. T. 17, Masson, Paris, 1307-1314.

JEANNEROD, M. (1974). Les deux mécanismes de la vision. La Recherche, 5 , 23-32.

JUNG, R. (1973). Visual perception and neurophysiology In: Handbook of Sensory Physiology. Vol. VII/3A, Ed. Jung Berlin-Heidelberg. New York 1-152.

LANDAU, W. H. (1967). Evoked potentials. In: The Neurosciences. A Study Program. Ed. Quarton, The Rockefeller University Press, New York, 469-482.
LEDERMAN, R. J., NOELL, W K. (1968). Fast-fiber system of rabbit optic nerve. Vision Research, 8, 1385-1398.

LISON, L. (1968). Statistique appliquée à la biologie expérimentale. Gauthier Villars, Paris, 207-210.

MAGNUSSEN, S. et GLAD, A. (1975). Brightness and darkness enchancement during flicker: Perceptual correlates of neuronal B and D systems in human vision. Experimental Brain Research 22, 399-413.

MARTY, R., SHERRER, J. (1964). Critères de maturation des systèmes afférents corticaux. Progress in Brain Research 4, 222-236.

MOLOTCHNIKOFF, S., DUBUC, M., BRUNETTE, J. R. (1975). Simultaneous recordings of visual cortex and superior colliculus field potentials in rabbit. Canadian Journal of Neurological Sciences, 2. 61-66.

MOLOTCHNIKOFF, S., DUBUC, M., BRUNETTE, J. R. (1976). Influence of the visual cortex upon visual evoked responses in the rabbit. Expérientia, 32, 72-73.

MOROTOMI, T., KITAJIMA, S. (1975). Enhancement of evoked responses to brief flashes and its correlation with "OFF" responses to pre-exposed light stimulation. Vision Research, 15, 272-276.

MUNTZ, W. R. A. (1962). Microelectrode recordings from the diencephalon of the frog (Rana pipiens). Journal of Neurophysiology, 25, 699-711.

PRINCE, J. H. (1964). The rabbit in eye research. Ed.: Prince Charles C. Thomas Sprinfield, 391.

RODIECK, R. W (1973). The vertebrate retina. W. H. Freeman and Company, San Francisco, 560-590.

SAWYER, C. H., EVERETT, J. 'W GREEN, J. D. (1954). The rabbit diencephalon in stereotaxic coordinates. Journal of comparative neurology 101, 801-824.
SCHAFFER, K. P (1970). Unit analysis and electrical stimulation of the optic tectum of rabbits and cats. Brain Behaviour and Evolution, 3, 222-240.

SCHILLER, P N., KOERNER, F (1967). Discharge characteristics of single units in superior colliculus of the alert Rhesus Monkey. Journal of Neurophysiology, 31, 52-62.

STÉRIADE, M. (1969). Physiologie des voies et des centres visuels. Masson, Paris, 54-109.

STERLING, P. (1971). Receptive field and synaptic organization of the superficial gray layer of the cat superior colliculus. Vision Research, Suppl. 3, 309-328.

SZENTAGOTHAÏ, J. (1973). Synaptology of the visual cortex. In: Handbook of Sensory physiology. Vol. VII/3B, Ed. R. Jung. Berlin-Heidelberg, 270-324.

TAMAI, M., OGAWA, I. (1972). Interaction between cortico-tectal and retino-tectal inputs as revealed by analysis of field potentials of the cat's superior colliculus. Tohoku Journal of Experimental Medicine 107, 127-142.

THOMPSON, J. M., WOOLSEY, C. N., TALBOT, S. A. (1950). Visual areas I and II of cerebral cortex of the rabbit. Journal of Neurophysiology, 13, 277-288.

VANEGAS, H., LAUFER, M., AMAT, J. (1974). The optic tectum. I. General configuration and cytoarchitecture. Journal of Comparative Neurology, 154, 43-60.

WERBLIN, F., DOWLING, J. E. (1969). Organization of the retina of the Mudpuppy Necturus Maculosus. II. Intracellular recordings. Journal of Neurophysiology, 32, 339-355.

WICKELGREN, B. G., STERLING, P. (1969). Influence of visual cortex on receptive fields in the superior colliculus of the Cat. Journal of Neurophysiology, 32, 16-23. 